\title{
An Analysis of the Reasons for the Acculturation of the South-to-North Scholars between the Liang and Chen Dynasties
}

\section{-Taking Yu Xin as an Example}

\author{
Xiancheng He \\ Research Institute of Sichuan Old Revolution Area Development, Sichuan University of Arts and Science, Dazhou, China \\ Email: xlightwhite@163.com
}

How to cite this paper: He, X.C. (2019) An Analysis of the Reasons for the Acculturation of the South-to-North Scholars between the Liang and Chen Dynasties. Open Journal of Social Sciences, 7, 84-91. https://doi.org/10.4236/jss.2019.76006

Received: May 15, 2019

Accepted: June 2, 2019

Published: June 5, 2019

Copyright $\odot 2019$ by author(s) and Scientific Research Publishing Inc. This work is licensed under the Creative Commons Attribution International License (CC BY 4.0).

http://creativecommons.org/licenses/by/4.0/

\begin{abstract}
After Emperor Wu ascended the throne in the Northern Zhou Dynasty, Yu Xin gradually adapted to and identified with the culture of the Northern Zhou Dynasty. There are four reasons for this: first, Emperor Wu of the Northern Zhou Dynasty attached great importance to Confucian-learning education; second, the great military, political and cultural advantages of the Northern Zhou Dynasty; third, Yu Xin's restoration of Confucian meritorious service and career consciousness; fourth, $\mathrm{Yu}$ Xin changed his understanding of the downfall of Liang Dynasty. The acculturation and political identity of the south-to-north bachelors reflected the process of their spiritual growth.
\end{abstract}

\section{Keywords}

The Northern Zhou Dynasty, Yu Xin, Acculturation, South-to-North Bachelors

\section{Introduction}

At the beginning of entering the north, Yu Xin was faced with a social and cultural environment totally different from that in the south and absolutely didn't have the exultation of the eastern Jin people when returning to the homeland from the northern expedition. During this period, he had obvious homesickness of his native land. He was dissatisfied with Yuwen Tai's destruction of Liang and thought that the way to become an official was not worth it, fearing of internal political strife of the Yuwen family. When Emperor Wu of the Northern Zhou Dynasty ascended the throne, Yu Xin had been in the north for six years. After that, he gradually adapted to and identified with the Northern Zhou's culture, 
and his attitude towards the Northern Zhou regime changed from the initial resistance to trying to integrate into the Northern Zhou regime. This paper takes $\mathrm{Yu} \mathrm{Xin}$ as an example to discuss the reasons for the acculturation of the south-to-north scholars between the Liang and Cheng Dynasties.

\section{Emperor Wu of the Northern Zhou Dynasty Attached Great Importance to Confucian-Learning Education}

During his eighteen years in power, Emperor Wu of the Northern Zhou Dynasty attached great importance to Confucian-learning education and seriously studied Confucianism himself and The Book of Rites as well as went to the Imperial College (in feudal China) to ask about Tao. For example, in the third year of Baoding (563), "He went to the Imperial College (in feudal China) to consult Yu Jin, Taifu and the Royal Highness Prince Yan, taking him as the 'old Mr.' (an official)" [1]. He also taught the Confucian classics to the public and private ethical Tao. History records, in the first year of Tianhe (566 year) "The emperor summoned his ministers to the Zhengwu hall and personally lectured them on The Book of Rites" [1]. After the destruction of the Northern Qi Dynasty, he vigorously collected Confucian classics, widely sought Confucian scholars, and advocated the Confucian "kingly way" and "benevolent rule". It can be said that the political thought of Emperor Wu takes Confucianism as the orthodoxy. The main purpose of the rulers of the Northern Zhou Dynasty to respect Confucianism was to win over the Han intellectuals, so as to establish their orthodox status, thus competing with the Chen Dynasty which was in the south of the Yangtze river. As we know, after the reform of Emperor Xiaowen of the Northern Wei Dynasty, the north once became the gathering place of the southern intellectuals. However, since the split of the Northern Wei Dynasty, most literary scholars entered the Northern Qi, and the literary soil of the Northern Zhou Dynasty was relatively weak. Leading figures in literary like Yu Xin and Wang Bao could be said to be the best opportunity for the Northern Zhou Dynasty to change its poor and weak soil. Therefore, Emperor $\mathrm{Wu}$ of the Northern Zhou Dynasty wanted to seize the opportunity to make a great effort, and thus Yu Xin, Wang Bao and other scholars who entered the north were the objects of his reuse.

\section{The Great Military, Political and Cultural Advantages of the Northern Zhou Dynasty}

When Yu Xin entered the north, the Northern Zhou Dynasty stood out in the struggle with the Northern Wi and Chen and gradually strengthened its strength. Especially after the Northern Zhou destroyed the Northern Qi, the Northern Zhou had huge advantages in military, political, cultural and other aspects compared with the southern Chen Dynasty.

First of all, in the military aspect, the Northern Zhou not only strengthened its military strength, but also had no worries about the wars with Chen. Just after 
the fall of the Northern Qi, Northern Zhou and Chen began a war. Emperor Xuan of Chen sent $\mathrm{Wu}$ Mingche to march on the northern expedition. However, he was defeated in Lvliang, losing about 30,000 soldiers. The battle of Lvliang was a very important battle between Zhou and Chen. "the elite soldiers of Chen dynasty were thus annihilated" [1] "south of the lower reaches of the Changjiang River was left decline, probably because of this reason" [2] and from then on, the Chen Dynasty suffered a sharp decline in military affairs.

Secondly, in terms of culture, after the Northern Zhou Dynasty destroyed the Northern Qi Dynasty, a large number of talents poured into the Northern Zhou Dynasty. Under the search for talents of Yuwen Yong, the Northern Zhou was full of talents. The literati Xue Daoheng, Lu Sidao, Sun Wanshou, Li Yuancao, Xin Deyuan, Yuan Xinggong, Yan Zhitui and so on all entered the Northern Zhou Dynasty from Qi and strengthened the literary team of the Northern Zhou Dynasty. In addition, the cultural advantages of the Northern Zhou Dynasty can also be learned in its friendly exchanges with the Chen Dynasty by sending envoys to each other. Previously, the southerners had culturally ridiculed the Northern Dynasty. In the second year of Taiqing in Liang Dynasty (548), Xu Ling "went to Wei (Eastern Wei), Wei arranged for his residence and feted guests. The day was so hot that Wei Jing, his host, mocked Xu Ling and said, 'Xu Changshi (Xu Ling) should be in charge of the heat today.' Xu Ling answered immediately, 'in the past, Wang Su came here and began to work out the etiquette for the state of Wei. And now I come to visit to let you know more about heat and cold.' Wei was very ashamed" [2]. Wei Shou ridiculed the Southern Dynasty geographically, while Xu Ling spoke in a turn of momentum, satirizing the Northern Dynasties culturally, which is more to the point. However, with Yu Xin, Wang Bao and other scholars entering the central Shaanxi plain, under whose influence the northern culture rose further and the southern culture became depleted and deficient. Xue Daoheng was one of the most famous scholars in the north. "Every time there is a book, south all chanted and recited" [3]. Thus it can be seen that the culture of the Northern Zhou Dynasty was increasingly prosperous, while the Chen dynasty showed the shortage of talents.

Third, in the political aspect, the orthodox status of Northern Zhou was clearer. The reform of Emperor Xiaowen of the Northern Wei made it the flag-bearer of the revival of Han culture and further sublimated the orthodox movement. After the division of the Northern Wei, the Western Wei made Chang'an its capital, occupying an advantageous geographical position and its real ruler $\mathrm{Yu}$ wen Tai also took a series of measures to establish its orthodox position, for example, imitating the Rites of Zhou, building six officers (namely heaven, earth, spring, summer, autumn, and winter) and building Fubing system. The rulers of the Northern Zhou Dynasty, especially Emperor Wu, made ritual and music, recruited talents, attached importance to diplomatic envoys, and flaxed themselves as a nation of Chinese rites and ceremonies. After the destruction of the Northern Qi and the unification of the north, it was not difficult to make people think 
that Chinese orthodoxy was in the north. In the face of this situation, Yu Xin also cannot help but issue the plaint of "My Great Zhou".

\section{Yu Xin's Restoration of Confucian Meritorious Service and Career Consciousness}

Yu Xin was born in a family with profound Confucianism and was influenced by Confucianism since childhood and thus devoted himself to the study of Confucian classics. The forty-one volume of Zhou Shu, Yu Xin Bibliography carries " $(\mathrm{Yu}) \mathrm{Xin}$ was pretty and knockout, handsome and heroic, talented and incredibly intelligent from childhood. He reads widely, especially good at Zuo's Commentary" [1]. In spite of this, Yu Xin in the Xiaoliang period was "not a scholar who devoted himself to academic research and governance of Confucian classics, nor a scholar who was in charge of government affairs, but a literati who played with literary skill" [4]. As a scholar, his main activities were accompanying banquets and traveling, and writing poems on the emperor's orders. It can be said that "living in a time of peace and prosperity, one does not know that there will be a loss of the country chaos disaster; being above the court, one is not aware of the urgent business of battles and formations; Keeping a salary supply, one does not know the hard work of farming; being domineers over the officials and people, one is unaware of the hard work and service of his people" [5]. Yu Xin, however, having suffered from the hou jing rebellion and the turmoil of jiangling, was full of the suffering of the destruction of the country. After entering the north, as time went by, Yu Xin's scar gradually healed, and the Confucian meritorious service and career consciousness gradually came out. Some researchers pointed out that, "the Confucian cultural value orientation deeply hidden in the heart of the southern period began to deeply affect his life and pursuit" [4]. He began to focus on the Northern Zhou Dynasty and realpolitik, and reflected on the fall and fall of the Liang Dynasty, so as to realize personal value in the realistic official career and preserve the interests of the family. "His ambition has been exhausted and the ambitious strategy is impossible to display", "When to display ambition and to see the vast sky again" and other lines are the reflection of Yu Xin's Confucian meritorious service and career consciousnes. It was because of Yu Xin's restoration of Confucian meritorious service and career consciousness that he changed his attitude towards the Northern Zhou Dynasty and tried to integrate into the regime of the Northern Zhou Dynasty.

\section{The Change of Yu Xin's Understanding of the Downfall of Liang Dynasty}

In the first year of Emperor Gong of the Western Wei Dynasty (554), Yu Jin, Yu wen hu, Yang Zhong, Wei Xiaokuan and so on were sent by Yuwen Tai to crusade against Jiangling and capture it in one fell swooping, killing the emperor and "capturing all kinds of officials and people for their own use. More than 
100,000 people were made slaves and only more than two hundred families were among the captives who were not taken as slaves" [1]. Yu's two sons and one daughter were both "killed one after another" in the war [6]. Yu himself started to live in a strange land in the north. At the beginning of entering the north, $\mathrm{Yu}$ Xin was so angry about the war that he strongly condemned Yuwen Tai for "being the son of a famous father, it was my fault that you were displaced between Jianghan" [6].

However, as time went by, Yu Xin began to look for the reasons for the collapse of Liang Dynasty from the Liang Dynasty itself, and finally realized that the Jinling disaster "although has something to do with the borrowed external forces, actually is stems from oneself" [6]. He began to blame the rulers who led to the death of Liang. Yu Xin furiously pointed out that the decay of the royal family was the root cause of the collapse of Liang Dynasty. Before the chaos of Hou Jing, the portent of war had been latent, but emperor Liangwu just talked about poetry and Taoism, obsessed with Buddhism and rarely engaged in government affairs, leading to military waste. At the same time, too much trust in minister Zhu Yi and others, allowance of Hou Jing's obedient, buried the time bomb of the decline of the Liang Dynasty. Therefore, Emperor Wu of Liang should bear the primary responsibility for the fall of the Liang Dynasty. As for the emperor Yuan of Liang, he was arrogant, jealous and cruel, and utterly isolated. It was because of the internal infighting of the royal family of the Liang Dynasty, the suspicion of brothers and the cannibalization of their flesh and blood that the external party was able to take advantage of the situation, which eventually led to the fall of the Liang Dynasty. Yu also accused Zhu Yi, Hou Jing and other treacherous ministers and traitors. Yu Xin accused minister Zhu Yi and others "treat the war as a joke and take the general impractical talk as the strategy of the court" [6]. For Hou Jing, Yu Xin even condemned his capricious, inhuman and disastrous crimes. "Hou Jing was capricious and constantly rebelled against his master ... Hou Jing was very ambitious and wanted to know the weight of the nine tripods ... wanted to travel through the Yi River, Luoshui River and Yellow River valleys in a carriage like King Wu of Qin dynasty" [6]. It was Hou Jing's cruelty and guile, the inability of the rulers and its officials of Liang Dynasty that led to the collapse of Liang Dynasty. After Yu Xin realized the real reason for the collapse of Liang Dynasty, he began to change his uncooperative attitude towards the Northern Zhou at the beginning of his entry into the north and gradually tried to integrate into the regime of the Northern Zhou.

\section{Conclusions}

$\mathrm{Yu}$ Xin entered the north and joined the ranks of literature in the Western Wei and Northern Zhou Dynasties. Although Yu Xin was a literary giant, he experienced a process from suspicion to trust in the Western Wei Dynasty. Anecdotes in the Court records "when $\mathrm{Yu}$ Xin arrived in the north at the beginning from the Southern Dynasty during the Liang Dynasty, scholars mostly despised him. Yu Xin showed them the Ode to the Dead Tree and then no one dared to 
speak" [7]. During the reign of Emperor Wu of the Northern Zhou Dynasty, Yu Xin was especially favored, and the making of rites and music was also depended on him. "After the entry of the Yuwen family, there was still a lack of music. When Jing state was pacified, a large number of musical instruments of the Liang Dynasty were obtained. Taizu began to implement the Rites of Zhou and Emperor Wu created the Dance of Cloud and Mountain for the first time. The establishment of national laws and regulations sought the opinions of Lu Bian and others and the article was written by Yu Xin" [6]. Sometimes the ruling group of the northern Zhou Dynasty held activities such as hunting, martial arts, banquets and excursions with Yu Xin. Their Kings were more in tune with the northern "like friends in days of simple life", among whom especially Yuwen You collected his collections after Yu's entry of Wei, synthesized twenty volumes, and made a preface to it, which obviously showed his love to Yu Xin. Yu Xin had a great influence on the literati of the Northern Zhou Dynasty. "The people of the court and the common people imitated the rhythm of his poems, which had a great influence on the literary world of the Northern Zhou Dynasty" [1]. It promoted the development of literature in the central Shaanxi plain, which laid a solid cultural foundation for the Northern Zhou Dynasty to unify the north.

But, on the other hand, Yu Xin also brought the flashy literary style of parallel prose into the north from the regions south of the Yangtze River. The forty-one volume of Book of Sui, Literary biography comments "After the reign in the year Datong of Liang ... Scholars vied with each other for the novelty and finesse of the writing, opened the floodgates of literary debauchery ... Xu Ling and Yu Xin had different goals in opening the style of literary extravagance. Their meaning of the text is simple and the wording is complex, more containing the feeling of mourning ... The Northern Zhou Dynasty destroyed the Liang Dynasty and the later Liang Dynasty. This kind of literary atmosphere was popular in Chang'an of the central Shaanxi plain and aimed high and impracticality prevails as a custom" [8]. Thus, "the relatively poor and declining culture in the central Shaanxi plain began to introduce a new literary style that flourished in the late Liang Dynasty, connecting with south of the lower reaches of the Changjiang River and Ye capitals on the track of development since the Wei and Jin Dynasties. The styles of the large scale of classics created by Yuwen Tai's efforts were spurned by his sons while the flashier style, which was despised, prevailed in the central Shaanxi plain [9].

During Yu Xin's 28 years of life in the north, he suffered both the pain of losing the country and the pain of leaving his hometown to adapt to the new cultural environment. After many changes, he finally stood up with a new posture and integrated into the new cultural environment and political life. It can be said that this process is the process of an intellectual heart's growth. We know that at the beginning of entering the north, Yu Xin criticized Yuwen Tai in his Ode to the Bamboo Stick and accused the Northern Zhou Dynasty of forcing him to 
serve as an official in Feeling Expressing. However, under the influence of the new political and cultural environment, Yu's personality has undergone subtle changes. Teng Wangyou mentioned him in the preface of Yu Xin's collected works as "Joy and anger are not shown on the face, while the Confucian moral code of being conscientious and considerate is always kept in mind." This assessment is obviously different from Yu's previous personality. In addition, Yu Xin also nirvanaed from an untroubled scholar to a literati and officialdom (in feudal China) concerned about the people of the world. Yu Xin rose all the way up in the Liang Dynasty with the advantages of the gentry and his literary talents. Moreover, during the reign of Emperor Wu of Liang, "there was no war in the south of the Yangtze river for 50 years", which made the king and his ministers not to know what is war and what is agricultural labor. In the second year of Taiqing (548), hou jing rebelled. "Emperor Jianwen of the Liang Dynasty ordered Yu to lead the civil and military officials in court more than 1000 people to camp in Zhuque hang (a place). When (Hou) jing comes, $(\mathrm{Yu})$ let others retreat firs." [1] Yu Xin suffered from the turmoil of Hou Jing and Jiang ling, and also saw the tragic separation of his wife and children. After entering the north, he saw that the ruler of the Northern Zhou Dynasty, especially the Emperor $\mathrm{Wu}$, Yuwen Yong was very concerned about the people. He realized that the corruption or clarity of a country's politics was closely related to the safety of its people. This kind of people-oriented understanding was reflected during his tenure of the sheriff of Hongnong county, Sixianzhongdafu (an official position, somewhat like the highest supervision) and the feudal provincial of Luo state. In $\mathrm{Yu}$ Xin's later works Lament for the South, the sentence lamenting the displacement of the common people can be seen everywhere. "Just like when encoutering Lu Ji who was going to Luoyang and seeing Wang Can who was away from home, no one would not hide his or her face to cry on hearing the sound of the running water of Long River and sighed deeply to the "Guan Mountain" because of homesickness" [6].

It can be said that south-to-north scholars' acculturation and political identity which was represented by $\mathrm{Yu}$ Xin, not only promoted the development of Northern Zhou literature and improved its barren literary soil, but also reflected the process of their nirvana, revealing the spiritual growth of scholars.

Of course, this essay can have a further study. During the Wei, Jin, Northern and Southern Dynasties, there were quite a few south-to-north bachelors. The time and reasons for their going to the north were different, leading to their different circumstances in the north. If these people are classified and studied, we can have a more detailed understanding of the adaptation process of the south-to-north bachelors in this period.

\section{Fund}

Project funded: General Project in Scientific Research Program of Sichuan Education Department (Humanities and Social Sciences) in 2018 (project num- 
ber: 18SB0614).

\section{Conflicts of Interest}

The author declares no conflicts of interest regarding the publication of this paper.

\section{References}

[1] Tang, Z.R. (1993) The Northern Biography on Southern Literature. Journal of Wuhan University (Humanities Edition), 6.

[2] Linghu, D.F. (1971) Zhou Shu. Zhonghua Book Company, Beijing.

[3] Yao, S.L. (1972) The History of the Chen. Zhonghua Book Company, Beijing.

[4] Yu, X. (2000) Notes of Yu Zishan Collection. Ni, F., Trans. Zhonghua Book Company, Beijing.

[5] Li, Y.S. (1974) The History of the Northern Dynasties. Zhonghua Book Company, Beijing.

[6] Zhou, Y. (2010) The Restoration of Yu's Feelings for South-to-North Scholars. Journal of Hunan Normal University (Social Sciences Edition), 4.

[7] Wei, Z. (1973) Book of Sui. Zhonghua Book Company, Beijing.

[8] Yan, Z.T. (1982) The Family Instructions of Master Yan. Shanghai Classics Publishing House, Shanghai.

[9] Zhang, Z. (1979) Court and Folk Notes. Zhonghua Book Company, Beijing. 